\title{
Including males in Canadian human papillomavirus vaccination programs: a policy analysis
}

\author{
Gilla K. Shapiro MPA MPP, Samara Perez BSc, Zeev Rosberger PhD
}

$\mathrm{T}$ he Canadian National Advisory Committee on Immunization (NACI) recommends human papillomavirus (HPV) vaccination for females aged 9-26 years (bivalent or quadrivalent vaccine) and males aged 9-26 years (quadrivalent vaccine) (Figure 1). ${ }^{1}$ All Canadian provinces and territories instituted school-based publicly funded quadrivalent HPV vaccination programs for females, albeit at different ages and dosing schedules. $^{2}$ To date, only Prince Edward Island, Alberta and Nova Scotia include boys in their school-based quadrivalent HPV vaccination programs. ${ }^{2-5}$ Recently, Manitoba and Quebec committed to expand their school-based HPV vaccination programs to include boys beginning in September 2016. ${ }^{6,7}$ However, moving to include boys in HPV vaccination programs across all Canadian jurisdictions is important to ensure equity in protection from HPV-associated disease for men. We examine the barriers to and opportunities for change in HPV vaccination policy by investigating the key factors that have influenced some provinces' decisions to incorporate boys into their programs, and we advocate for all jurisdictions to expand their HPV vaccination programs to include boys.

\section{What is the burden of HPV disease?}

Human papillomavirus is the most common sexually transmitted infection among Canadians. ${ }^{8}$ That HPV infection causes cervical cancer in women is well known. It is also associated with anogenital warts, and cancers of the penis, anus, oral cavity, vulva, vagina and oropharynx. ${ }^{1,8} \mathrm{~A}$ growing burden of HPV-associated cancers in males, with an increasing incidence of anal and oral cancers, has been reported., ${ }^{9,10}$ Another serious, albeit rare, consequence of oral HPV infection is recurrent respiratory papillomatosis. ${ }^{9}$ In developed countries, where screening programs for cervical cancer exist, some argue that the risk of HPV-related cancer is similar in both sexes. ${ }^{11}$ Sexually active heterosexual men infected with HPV also represent a source of infection for women who have not been vaccinated.
Men who have sex with men (MSM) have been identified as a particularly high-risk group with increased susceptibility to HPV and HPVassociated diseases. ${ }^{12-14}$ Preliminary evidence has also shown that HPV may increase risk of HIV acquisition. ${ }^{15}$ These costly and burdensome conditions are preventable, ${ }^{16}$ yet no programs of screening for HPV infection are currently available to males.

\section{What is the efficacy of HPV vaccination?}

Numerous randomized controlled trials have established the safety and efficacy of the bivalent and quadrivalent HPV vaccines, ${ }^{17-19}$ which demonstrate strong immunogenicity in both sexes. ${ }^{20,21}$ Serious adverse events as a result of the HPV vaccines are rare, and most reported reactions are of pain at the injection site. 1,21,22 Both HPV vaccines' safety has been assured by the World Health Organization, the Centers for Disease Control and Prevention, the NACI and other international advisory committees. ${ }^{23-25}$ In terms of the HPV vaccine's real-world impact, epidemiologic evidence has found significant reductions in HPVrelated infections (77\% decrease in prevalence),

\section{- KEY POINTS}

- The prevalence of human papillomavirus (HPV)-associated cancers in men is increasing, and males may transmit HPV to female partners.

- The HPV vaccine is safe and effective, and has demonstrated strong immunogenicity.

- A number of obstacles to uptake of the HPV vaccine in boys include not receiving a recommendation from a doctor or health care provider, lack of information about the HPV vaccine, negative attitudes toward the HPV vaccine or other vaccines, HPV being overidentified as a woman's disease, cost and logistical challenges.

- Some provinces have decided to fund the HPV vaccine for boys following clearer evaluation of cost-effectiveness models, reduction of vaccine costs, consideration of principles of equity and public advocacy efforts.

- Including boys in HPV vaccination programs across all Canadian jurisdictions will ensure equity in protection from HPV-associated disease for men. 
reductions in genital warts ( $>90 \%$ decrease) and reductions in high-grade cervical lesions in vaccinated female cohorts. ${ }^{26}$

\section{What obstacles may thwart HPV vaccination for boys in Canada?}

In 2008, before the HPV vaccine was approved for boys by the NACI, one study examined the intention of 1381 Canadian parents to provide their sons with the HPV vaccine and found that $68 \%$ intended to vaccinate their sons. ${ }^{27} \mathrm{How}-$ ever, in 2014, at a time when the HPV vaccine was available for boys, another study evaluated a national sample of 3117 Canadian parents of boys and found that only $5 \%$ of parents intended to vaccinate their sons and only $1 \%$ reported they had vaccinated their sons. ${ }^{28}$ This discordance suggests obstacles to introducing the HPV vaccine programs for boys.

\section{Misconceptions}

Some of the identified obstacles to acceptance of the HPV vaccine by parents of boys include not receiving a recommendation from a doctor or health care provider, lack of information about the HPV vaccine, and negative attitudes toward the HPV vaccines or other vaccines. ${ }^{27,29,30} \mathrm{~A}$ ban of the HPV vaccine in some Catholic schools ${ }^{31}$ may have suggested that receiving the HPV vaccine contributes to sexual disinhibition and related adverse outcomes (e.g., younger age at first intercourse, increased number of sexual partners and reduced use of contraception). ${ }^{27,32}$ However, little evidence has been produced to substantiate these claims, ${ }^{33}$ and Canadian parents rarely report these reasons as barriers to vaccination. ${ }^{28}$ The media also contributes to influencing public opinion, and a number of sensational articles on the HPV vaccine have been published in Canadian media (e.g., a Toronto Star article that has since been retracted). ${ }^{34}$

\section{"A woman's vaccine"}

Some have argued that a barrier to HPV vaccine uptake among boys is the "feminization of HPV," meaning that the HPV vaccine has been overidentified as a preventive tool for a woman's disease. ${ }^{35}$ For example, Merck's "One Less" public campaign focused exclusively on prevention of cervical cancer. ${ }^{36}$ Campaigns like these combined with the initial exclusive funding of

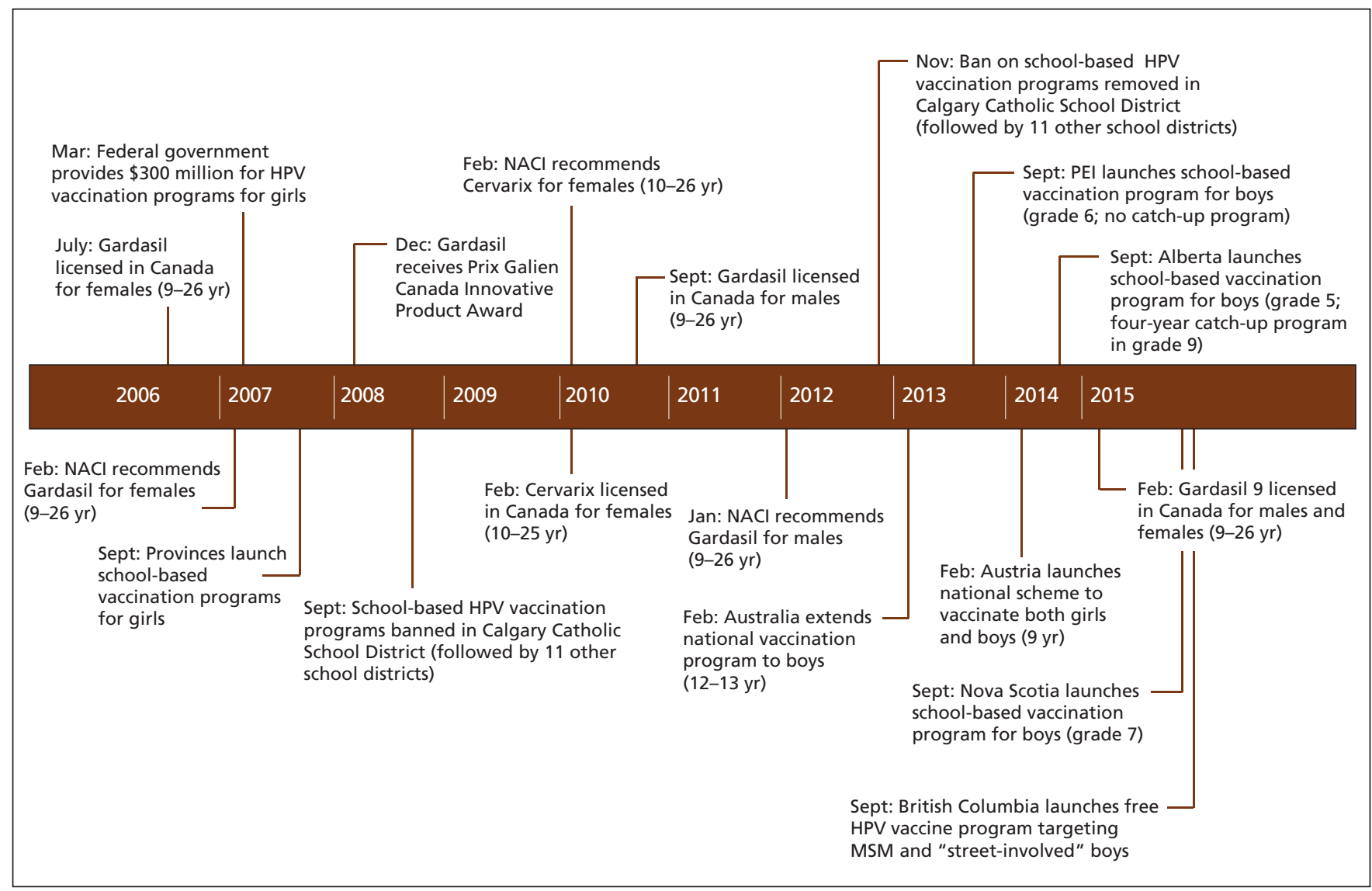

Figure 1: Timeline of events affecting the human papillomavirus (HPV) vaccination program in Canada. ${ }^{1,2}$ MSM $=$ men who have sex with $\mathrm{men}, \mathrm{NACl}=$ National Advisory Committee on Immunization. 
the HPV vaccine for females may well have affected the public's perception of the vaccine as "a woman's vaccine," influencing both parents and doctors. A recent content analysis of Canadian media showed that less than half of print articles on the HPV vaccine reported on male eligibility and fewer reported on schoolbased programs for boys. ${ }^{37}$ It is therefore unsurprising that in 2014 more than half of Canadian parents were unaware that males could receive the HPV vaccine. ${ }^{28}$

\section{Belief in herd immunity}

As it became clearer that HPV-associated diseases are also problematic for boys, policy-makers anticipated that the female-only HPV vaccination programs would confer protection to males. ${ }^{16,38}$ Indeed, a 2015 systematic review and meta-analysis of population-level effects in highincome countries found that female vaccination has led to reductions in anogenital warts in males, supporting the idea of herd immunity. ${ }^{39}$ However, as discussed below, there are some important limitations to reliance on female immunity.

\section{Cost}

A potential obstacle to HPV vaccine uptake among boys in many provinces is the cost of the vaccine. The estimated price for each dose of the vaccine is about $\$ 150$, and multiple doses are recommended. It has also been argued that when the government does not fund a vaccine, Canadians may perceive vaccination as superfluous or nonbeneficial. ${ }^{40}$ Furthermore, when a vaccine is not provided as part of a government-funded, school-based program, parents must negotiate the logistical challenges of arranging vaccination themselves (e.g., scheduling appointments and making private insurance claims).

The cost of the HPV vaccine has led to hesitation on the part of policy-makers when considering provincial vaccination programs for boys. As BC provincial health officer Dr. Perry Kendall explained, "There's no question that if the vaccine was cheap and affordable ... we would reconsider the option." ${ }^{41}$ Some provinces have not expanded the HPV vaccination program to boys citing poor cost-effectiveness. ${ }^{42,43}$ Indeed, multiple early modelling studies reported that vaccinating boys is less costeffective than achieving high uptake rates in females. ${ }^{44,45}$ However, many early economic models did not account for marginal administration costs, inadequate uptake rates in females, the burden of noncervical diseases (e.g., including oral cancer and genital warts), the MSM population, sexual exploration with same-sex partners, individuals engaging in sexual activity outside their country or "herd," or the recent recommended shift from three to two doses of the vaccine..$^{46,47}$

\section{What new evidence could support more widespread HPV vaccination programs for boys?}

Factors particularly relevant to some provinces' decision to fund the HPV vaccine for boys have been closer evaluation of cost-effectiveness models, reduction of vaccine costs, consideration of principles of equity, and public advocacy efforts.

A 2009 review of the cost-effectiveness of the HPV vaccine in developed countries cautioned that the incremental effectiveness of vaccinating males varies when coverage rates in females is low (e.g., < 80\%). ${ }^{44}$ Unfortunately, female vaccination rates are not consistently reaching levels that would confer adequate protection via herd immunity in many Canadian provinces. ${ }^{2}$ Although vaccination completion rates fluctuate annually, rates of HPV vaccination among females were $61 \%$ in Alberta in $2011 / 12,76 \%$ in Nova Scotia in 2011/12 and $85 \%$ in PEI in $2013 / 14 .^{2,48}$ Many modelling studies do not consider that Canadian men will not be protected if they have sexual contact with individuals from countries without an HPV vaccine program or with an HPV vaccine program that has very low uptake rates (e.g., Japan). ${ }^{49}$

Contradicting earlier modelling studies, ${ }^{44,45}$ some recent economic analyses have suggested that routine HPV vaccination for boys is costeffective. ${ }^{46,49}$ A 2015 study reported that offering the HPV vaccine to Canadian males could save $\$ 8$ million to $\$ 28$ million over the lifetime of the modelled cohort, ${ }^{50}$ but, crucially, this study did not model for the indirect protection that heterosexual males would receive from HPV vaccination in females through herd immunity. Notably, important differences exist in the methods and modelling assumptions used different modelling studies. ${ }^{44,46,50}$ Disparities largely depend on the assumed vaccine and administration costs, whether cost reductions related to all HPV-related diseases were considered, whether the MSM population was considered, assumed sexual behaviour and partnership duration, and whether female coverage was suboptimal. ${ }^{16,47}$ Clearly, it is important to closely evaluate the particulars of different cost-effectiveness models. Future cost-effectiveness analyses of male HPV vaccination should also examine the newly licensed non- 
avalent vaccine that will protect against five additional oncogenic types of HPV..$^{51}$

\section{What can be done to overcome the cost barrier?}

A key factor in ensuring that provinces will fund vaccination of boys is reducing the cost of the vaccine. Engaging in vaccine price negotiations with pharmaceutical companies will help, particularly if provinces collaborate to do this. In addition, the WHO and NACI have now changed their recommendation to suggest adequacy of two (rather than three) doses of the bivalent and quadrivalent HPV vaccine for nonimmunocompromised children 9-14 years of age..$^{25,52}$ This will reduce the costs of male HPV vaccination by one dose per child, with attendant administrative cost savings. The province of Manitoba's commitment to offer the quadrivalent HPV vaccine to boys (as of September 2016) was accompanied by the decision to change from a three- to two-dose schedule..$^{53}$ Given that $\$ 300$ million of federal government funding was important in initiating female HPV vaccination programs across the provinces in 2007 (Figure 1$),{ }^{54}$ further federal funding could help to support a national vaccination strategy for boys.

\section{What about equity?}

It is important to note that not all vaccination programs are cost-effective. As noted by Stanley, ${ }^{10}$ "vaccination against meningococcal infection in children is not cost effective, for example, but society accepts it because the prevention of such a serious disease is a worthwhile public-health goal." The group most obviously affected by the exclusion of boys from HPV vaccination programs is MSM, a group known to have higher rates of HPV infection. . $^{1,22}$ Excluding boys discriminates against their well-being. In 2014, UK policy-makers suggested closing this gap by offering funded vaccination to men between 16 and 40 years of age who identify as gay or bisexual in genitourinary medicine and HIV clinics. ${ }^{55}$ In July 2015, British Columbia also announced plans to provide the quadrivalent HPV vaccine to MSM and "street-involved" boys. ${ }^{56}$ However, targeting gay men creates further ethical dilemmas, including failing to provide MSM with optimal immunity that is conferred if the vaccine is administered at a young age (many men may not identify as gay or bisexual until their twenties or thirties), requiring young men to openly identify themselves as MSM to receive health services, confronting difficult issues regarding consent, instituting a policy that may stigmatize gay individuals, and excluding heterosexual males who remain at risk. ${ }^{57}$ Some argue that the female-only HPV vaccination policy discriminates not only against MSM, but against all males. ${ }^{10}$ Men, particularly those who are uninsured and cannot afford the vaccine without public programs, will have reduced access to the health benefits of HPV vaccination.

\section{What about public advocacy?}

Advocacy efforts have been instrumental to extending the HPV vaccination programs to males. The Canadian Cancer Society has called for vaccination of "boys and young men between the ages of nine and $26 \ldots$ to help reduce their risk of HPV-related cancers and genital warts. ${ }^{58}$ HPV Canada has also emphatically supported HPV vaccination for boys. ${ }^{59}$ The medical community has advocated for HPV vaccination for boys, and, as reported by $C B C$ News, the Canadian Medical Association "strongly supports the call for public funding" for vaccination for both sexes. ${ }^{60}$ The Canadian Paediatric Society has also recommended male HPV vaccination to parents, ${ }^{61}$ and the Canadian Pharmacists Association recently released a strong statement that "the lack of access to HPV vaccination programs for young men in Canada is needlessly putting the health of Canadians at risk." "62 Similarly, the newsletter of the BC Pediatric Society recently encouraged its readers to write to their local member of the legislative assembly (MLA) to voice support for expanding HPV vaccination programs to include all boys. ${ }^{63}$ Advocacy efforts within the government have been particularly important to instituting policy change. For example, MLA Gordon Gosse, who was diagnosed with throat cancer, was influential in having the HPV vaccine program extended to boys in Nova Scotia. ${ }^{64}$ Such advocacy will continue to be extremely important in influencing policy change across other Canadian jurisdictions.

\section{Conclusion}

Canada has been an international leader in initiating public HPV vaccination programs for males in some jurisdictions, alongside Australia and Austria. It is important for policy-makers to be cognizant that HPV infection causes cancer in males as well as females, that heterosexual males will not consistently be protected by herd immunity with current rates of HPV vaccination in females, and that MSM will not be protected by female-only programs.

\section{References}

1. National Advisory Committee on Immunization. Update on human papillomavirus (HPV) vaccines. Canada Communicable Disease Report. Vol. 38. Ottawa: Public Health Agency of Canada; 2012.

2. Recommendations for human papillomavirus immunization programs. Ottawa: Canadian Immunization Committee, Public 
Health Agency of Canada; 2014. Available: http://publications gc.ca/collections/collection_2014/aspc-phac/HP40-107-2014-eng .pdf (accessed 2016 Apr. 12).

3. Bonanni P, Bechini A, Donato R, et al. Human papilloma virus vaccination: impact and recommendations across the world. Ther Adv Vaccines 2015;3:3-12.

4. Grant K. Nova Scotia to include boys in HPV vaccination schedule. Globe and Mail [Toronto] 2015 Apr. 10. Available: www. theglobeandmail.com/life/health-and-fitness/health/nova-scotia-to -include-boys-in-hpv-vaccination-schedule/article23886885 (accessed 2016 Feb. 2).

5. Colbert Y. HPV vaccine for Nova Scotia boys called 'groundbreaking.' CBC News 2015 Apr. 13. Available: www.cbc.ca/ news/canada/nova-scotia/hpv-vaccine-for-nova-scotia-boys-called -groundbreaking-1.3031169 (accessed 2016 Apr. 7).

6. Manitoba's immunization program: vaccines offered free-ofcharge (eligibility criteria for publicly-funded vaccines). Winnipeg: Communicable Disease Control. Manitoba Health, Healthy Living and Seniors. 2015. Available: www.gov.mb.ca/ health/publichealth/cdc/vaccineeligibility.html (accessed 2016 Apr. 12).

7. Human papillomavirus (HPV) vaccine. Quebec: Gouvernement du Québec; 2016. Available: http://sante.gouv.qc.ca/en/ conseils-et-prevention/vaccin-contre-les-infections-par-les-virus -du-papillome-humain-vph (accessed 2016 Apr. 12).

8. Anic GM, Giuliano AR. Genital HPV infection and related lesions in men. Prev Med 2011;53(Suppl 1):S36-41.

9. Palefsky JM. Human papillomavirus-related disease in men: not just a women's issue. J Adolesc Health 2010;46(Suppl):S12-9.

10. Stanley M. Perspective: vaccinate boys too. Nature 2012;488:S10.

11. Hartwig S, Syrjanen S, Dominiak-Felden G, et al. Estimation of the epidemiological burden of human papillomavirusrelated cancers and non-malignant diseases in men in Europe: a review. BMC Cancer 2012;12:30

12. Zou H, Tabrizi SN, Grulich AE, et al. Early acquisition of anogenital human papillomavirus among teenage men who have sex with men. J Infect Dis 2014;209:642-51.

13. Latini A, Dona MG, Ronchetti L, et al. Prevalence of anal human papillomavirus infection and cytologic abnormalities among HIV-infected and HIV-uninfected men who have sex with men. J Int AIDS Soc 2014;17(Suppl 3):19662.

14. Glick SN, Feng Q, Popov V, et al. High rates of incident and prevalent anal human papillomavirus infection among young men who have sex with men. J Infect Dis 2014;209:369-76.

15. Houlihan CF, Larke NL, Watson-Jones D, et al. Human papillomavirus infection and increased risk of HIV acquisition. A systematic review and meta-analysis. AIDS 2012;26:2211-22.

16. Crosignani P, De Stefani A, Fara GM, et al. Towards the eradication of HPV infection through universal specific vaccination. BMC Public Health 2013;13:642.

17. Ferris D, Samakoses R, Block SL, et al. Long-term study of a quadrivalent human papillomavirus vaccine. Pediatrics 2014 134:e657-65.

18. Macartney KK, Chiu C, Georgousakis M, et al. Safety of human papillomavirus vaccines: a review. Drug Saf 2013;36:393-412.

19. Palefsky JM, Giuliano AR, Goldstone S, et al. HPV vaccine against anal HPV infection and anal intraepithelial neoplasia. N Engl J Med 2011;365:1576-85.

20. Hillman RJ, Giuliano AR, Palefsky JM, et al. Immunogenicity of the quadrivalent human papillomavirus (type 6/11/16/18) vaccine in males 16 to 26 years old. Clin Vaccine Immunol 2012;19:261-7.

21. Stillo M, Carrillo Santisteve P, Lopalco PL. Safety of human papillomavirus vaccines: a review. Expert Opin Drug Saf 2015;14:697-712.

22. Shearer BD. HPV vaccination: understanding the impact on HPV disease. Winnipeg: National Collaborating Centre for Infectious Disease; 2011. Available: https://centreinfection.s3.amazonaws com/wp/sites/2/2015/04/05210315/PP_34_EN.pdf (accessed 2015 Mar. 15).

23. World Health Organization. Human papillomavirus vaccines WHO position paper, October 2014 — recommendations. Vaccine 2015;33:4383-4

24. HPV vaccines: vaccinating your preteen or teen. Atlanta: Centers for Disease Control and Prevention; 2015. Available: www. cdc.gov/hpv/parents/vaccine.html (accessed 2015 Jan. 7)

25. National Advisory Committee on Immunization. Update on the recommended human papillomavirus vaccine immunization schedule. Ottawa: Public Health Agency of Canada; 2015.

26. Garland SM. The Australian experience with the human papillomavirus vaccine. Clin Ther 2014;36:17-23.

27. Ogilvie GS, Remple VP, Marra F, et al. Intention of parents to have male children vaccinated with the human papillomavirus vaccine. Sex Transm Infect 2008;84:318-23.
28. Perez S, Shapiro GK, Brown CA, et al. 'I didn't even know boys could get the vaccine': parents' reasons for human papillomavirus (HPV) vaccination decision making for their sons. Psychooncology 2015;24:1316-23.

29. Dahlström LA, Tran TN, Lundholm C, et al. Attitudes to HPV vaccination among parents of children aged 12-15 years - a population-based survey in Sweden. Int J Cancer 2010;126: 500-7.

30. Reiter PL, McRee AL, Kadis JA, et al. HPV vaccine and adolescent males. Vaccine 2011;29:5595-602.

31. Guichon JR, Mitchell I, Buffler P, et al. Citizen intervention in a religious ban on in-school HPV vaccine administration in Calgary, Canada. Prev Med 2013;57:409-13.

32. Lenehan JG, Leonard KC, Nandra S, et al. Women's knowledge, attitudes, and intentions concerning Human Papillomavirus vaccination: findings of a waiting room survey of obstetrics-gynaecology outpatients. J Obstet Gynaecol Can 2008;30:489-99.

33. Kasting ML, Shapiro GK, Rosberger Z, et al. Tempest in a teapot: a systematic review of HPV vaccination and risk compensation research. Hum Vaccin Immunother 2016;12:1435-50.

34. Bruser D, Mclean J. HPV vaccine Gardasil has a dark side. Toronto Star 2015 Feb. Available: https://web.archive.org/ web/20150205215614/http://www.thestar.com/news/canada/2015 /02/05/hpv-vaccine-gardasil-has-a-dark-side-star-investigation-finds .html (accessed 2016 Apr. 15).

35. Daley EM, Vamos CA, Zimet GD, et al. The feminization of HPV: reversing gender biases in US human papillomavirus vaccine policy. Am J Public Health 2016;106:983-4.

36. Grantham S, Ahern L, Connolly-Ahern C. Merck's One Less Campaign: using risk message frames to promote the use of Gardasil® in HPV prevention. Commun Res Rep 2011;28:318-26.

37. Perez S, Fedoruk C, Shapiro G, et al. Giving boys a shot: the HPV vaccine's portrayal in Canadian newspapers. Health Com mun 2016;31:1527-38.

38. Paul Y. Herd immunity and herd protection. Vaccine 2004; 22:301-2.

39. Drolet M, Benard E, Boily MC, et al. Population-level impact and herd effects following human papillomavirus vaccination programmes: a systematic review and meta-analysis. Lance Infect Dis 2015;15:565-80.

40. Scheifele DW, Ward BJ, Halperin SA, et al. Approved but non-funded vaccines: accessing individual protection. Vaccine 2014:32:766-70.

41. Weeks C. Why this doctor says leaving boys out of HPV vaccination program doesn't make sense. Globe and Mail [Toronto] 2015 Sept. 9. Available: www.theglobeandmail.com/life/health-and -fitness/health/leaving-boys-out-of-hpv-vaccination-program-doesnt -make-sense-doctor/article26283436 (accessed 2016 Jan. 8).

42. Eggertson L. Provinces weighing HPV vaccination of boys CMAJ 2012;184:E250-1.

43. The HPV Vaccine, free for boys too? CTV News Montreal 2014 Jan. 14. Available: http://montreal.ctvnews.ca/the-hpv-vaccine -free-for-boys-too-1.1639708 (accessed 2016 Feb. 2).

44. Brisson M, Van de Velde N, Boily MC. Economic evaluation of human papillomavirus vaccination in developed countries. Public Health Genomics 2009;12:343-51.

45. Seto K, Marra F, Raymakers A, et al. The cost effectiveness of human papillomavirus vaccines: a systematic review. Drugs 2012;72:715-43.

46. Ryser MD, McGoff K, Herzog DP, et al. Impact of coveragedependent marginal costs on optimal HPV vaccination strategies. Epidemics 2015;11:32-47.

47. Olsen J, Jorgensen TR. Revisiting the cost-effectiveness of universal HPV-vaccination in Denmark accounting for all potentially vaccine preventable HPV-related diseases in males and females. Cost Eff Resour Alloc 2015;13:4.

48. McClure CA, MacSwain MA, Morrison H, et al. Human papillomavirus vaccine uptake in boys and girls in a school-based vaccine delivery program in Prince Edward Island, Canada. Vaccine 2015;33:1786-90.

49. Hanley SJ, Yoshioka E, Ito Y, et al. HPV vaccination crisis in Japan. Lancet 2015;385:2571.

50. Graham DM, Isaranuwatchai W, Habbous S, et al. A costeffectiveness analysis of human papillomavirus vaccination of boys for the prevention of oropharyngeal cancer. Cancer 2015; 121:1785-92.

51. Use of 9-valent human papillomavirus (HPV) vaccine: updated HPV vaccination recommendations of the Advisory Committee on Immunization Practices. MMWR 2015;64:300-4. Available: www. cdc.gov/mmwR/preview/mmwrhtml/mm6411a3.htm (accessed 2016 Jan. 8).

52. World Health Organization. Human papillomavirus vaccines: WHO position paper, October 2014. Wkly Epidemiol Rec 2014;89:465-91. 
53. Province expands HPV immunization program to include males [news release]. Government of Manitoba; 2015 Oct. 21. Available: https://news.gov.mb.ca/news/index $\cdot$ html archive $=\&$ item=36477 (accessed 2015 Dec. 1 ).

54. Steben M. Do you approve of spending $\$ 300$ million on HPV vaccination?: yes. Can Fam Physician 2008;54:174, 176, 178, 180.

55. Interim statement on HPV vaccination of men who have sex with men. London (UK): Department of Health and Public Health; 2014. Available: www.gov.uk/government/publications/ interim-statement-on-hpv-vaccination-of-men-who-have-sex-with -men (accessed 2015 Mar. 2).

56. HPV immunization program expanded to vulnerable boys. BC Gov News. 2015 July 7. Available: https://news.gov.bc.ca/stories /hpv-immunization-program-expanded-to-vulnerable-boys (accessed 2016 Apr. 12).

57. Shapiro G, Guichon J, Perez S, et al. British Columbia's flawed HPV vaccination policy. Montréal: Institute for Research on Public Policy; 2015. Available: https://policyoptions.irpp.org/ issues/september-2015/british-columbias-flawed-hpv-vaccination -policy (accessed 2015 Dec. 1).

58. A game changer. Believe 2013; Spring/Summer: 10. Available: www.cancer.ca/ /media/cancer.ca/AB/about us/BelieveMagazine 2013_Spring_AB.pdf (accessed 2015 Dec. 1).

59. HPV Canada [home page] Available: http://hugyourkids.org/ index.html (accessed 2016 Feb. 2).

60. Sagan A. HPV vaccine: why boys are less likely to get it. $C B C$ News 2014 Sept. 5. Available: www.cbc.ca/news/health/hpv -vaccine-why-boys-are-less-likely-to-get-it-1.2756037 (accessed 2015 Mar. 2)
61. Moore DL. Your child's best shot: a parent's guide to vaccination. Ottawa: Canadian Paediatric Society; 2015.

62. CPhA calls for HPV strategy for young men to save lives [news release]. Ottawa: Canadian Pharmacists Association; 2015 July 6. Available: www.pharmacists.ca/index.cfm/news-events/ news/cpha-calls-for-hpv-strategy-for-young-men-to-save-lives (accessed 2015 Dec. 1).

63. The prescription pad [newsletter]. Vancouver: BC Pediatric Society; 2015.

64. HPV vaccine may be offered to boys in Nova Scotia. CBC News 2014 Sept. 26.

Affiliations: Department of Psychology (Shapiro, Perez, Rosberger); Departments of Psychiatry and Oncology (Rosberger), McGill University; Lady Davis Institute for Medical Research (Shapiro, Perez, Rosberger), Jewish General Hospital, Montréal, Que.

Contributors: Gilla Shapiro conceived, drafted and revised all versions of the article. Samara Perez and Zeev Rosberger provided feedback on all versions. All of the authors approved the final version to be published and agreed to act as guarantors of the work.

Acknowledgements: The authors thank Antonia Maoini and Daniel Weinstock for their helpful comments on an earlier version of this article. Gilla Shapiro and Samara Perez are Vanier Canada Graduate Scholars, and Gilla Shapiro is a Queen Elizabeth II Diamond Jubilee Scholar. 